\title{
Article \\ Definition of Biologically Distinct Groups of Conjunctival Melanomas According to Etiological Factors and Implications for Precision Medicine
}

\author{
Sophie Gardrat ${ }^{1}$, Alexandre Houy ${ }^{2}$ (D), Kelly Brooks ${ }^{3,4}$, Nathalie Cassoux ${ }^{5}$, Raymond Barnhill ${ }^{6}$, Stéphane Dayot ${ }^{2}$, \\ Ivan Bièche ${ }^{7}$, Virginie Raynal ${ }^{8}$, Sylvain Baulande ${ }^{8}$, Richard Marais ${ }^{3}$, Sergio Roman-Roman ${ }^{9}$, \\ Marc-Henri Stern ${ }^{2}$ ad and Manuel Rodrigues ${ }^{2,10, *(\mathbb{D})}$
}

\section{check for}

updates

Citation: Gardrat, S.; Houy, A.; Brooks, K.; Cassoux, N.; Barnhill, R.; Dayot, S.; Bièche, I.; Raynal, V.; Baulande, S.; Marais, R.; et al. Definition of Biologically Distinct Groups of Conjunctival Melanomas According to Etiological Factors and Implications for Precision Medicine. Cancers 2021, 13, 3836. https:// doi.org/10.3390/cancers13153836

Academic Editor: Alan Spatz

Received: 6 July 2021

Accepted: 26 July 2021

Published: 30 July 2021

Publisher's Note: MDPI stays neutral with regard to jurisdictional claims in published maps and institutional affiliations.

Copyright: (c) 2021 by the authors. Licensee MDPI, Basel, Switzerland. This article is an open access article distributed under the terms and conditions of the Creative Commons Attribution (CC BY) license (https:/ / creativecommons.org/licenses/by/ $4.0 /)$.
1 INSERM U830, DNA Repair and Uveal Melanoma (D.R.U.M.), Equipe Labellisée par la Ligue Nationale Contre le Cancer and PSL Research University, Department of Biopathology, Institut Curie, PSL Research University, F-75005 Paris, France; sophie.gardrat@curie.fr

2 INSERM U830, DNA Repair and Uveal Melanoma (D.R.U.M.), Equipe Labellisée par la Ligue Nationale Contre le Cancer, Department of Genetics, Institut Curie, PSL Research University, F-75005 Paris, France; alexandre.houy@curie.fr (A.H.); stephane.dayot@curie.fr (S.D.); marc-henri.stern@curie.fr (M.-H.S.)

3 Molecular Oncology Group, CRUK Manchester Institute, The University of Manchester, Alderley Park, Manchester M13 9PL, UK; Kelly.Brooks@qimrberghofer.edu.au (K.B.);

Richard.Marais@cruk.manchester.ac.uk (R.M.)

4 QIMR Berghofer Medical Research Institute, Brisbane, QLD 4006, Australia

5 Department of Ocular Oncology, Faculty of Medicine, Institut Curie, Université de Paris Descartes, F-75005 Paris, France; nathalie.cassoux@curie.fr

6 Department of Biopathology, Institut Curie, PSL Research University, F-75005 Paris, France; raymond.barnhill@curie.fr

7 INSERM U1016, Institut Curie, Department of Genetics, Faculty of Pharmaceutical and Biological Sciences, Université de Paris, F-75005 Paris, France; ivan.bieche@curie.fr

8 Institut Curie Genomics of Excellence (ICGex) Platform, Institut Curie, PSL Research University, F-75005 Paris, France; virginie.raynal@curie.fr (V.R.); sylvain.baulande@curie.fr (S.B.)

9 Translational Research Department, Institut Curie, PSL Research University, F-75005 Paris, France; sergio.roman-roman@curie.fr

10 Department of Medical Oncology, Institut Curie, PSL Research University, F-75005, Paris, France

* Correspondence: manuel.rodrigues@curie.fr; Tel.: +33-156245991

Simple Summary: Conjunctival melanoma (ConjMel) is a rare but potentially deadly eye tumor developing on the ocular mucosal surface, which is partially exposed to sunlight. The relationships between potential etiological factors such as ultraviolet exposure and ConjMel mutational landscape have not been precisely described in large cohorts. Here, we report the sequencing of 400 cancer genes in 47 primary ConjMel and show several associations between mutations and etiological factors. $B R A F$ - and CDKN2A-mutated ConjMel affect younger patients while NF1-mutated tumors tend to develop in older ones. CTNNB1 mutations are more frequent in nevi-derived ConjMel, suggesting that the Wnt pathway is pivotal in their tumorigenesis. We further identified concomitant KIT / SF3B1 mutations in $B R A F / R A S$-wild type, sun-protected tumors, suggesting a similar profile as previously observed in genital and anorectal melanomas, thus unveiling a distinct, mucosal-specific, tumorigenic pathway. Finally, we report for the first time new targetable oncogenic mutations, opening new therapeutic options for these patients.

Abstract: Conjunctival melanoma (ConjMel) is a potentially deadly ocular melanoma, originating from partially sunlight-exposed mucosa. We explored the mutational landscape of ConjMel and studied the correlation with etiological factors. We collected 47 primary ConjMel samples and performed next-generation sequencing of 400 genes. Hotspot mutations in BRAF, NRAS, HRAS, and KIT were observed in 16 (34\%), 5 (11\%), 2, and 2 cases, respectively. Patients with BRAF and CDKN2A-mutated ConjMel tended to be younger while the NF1-mutated one tended to be older. The eight tumors arising from nevi were enriched in CTNNB1 mutations (63\% vs. 8\%; Fisher's exact $p$-test $=0.001$ ) compared to non-nevi ConjMel and five were devoid of $B R A F, R A S, N F 1$, or KIT mutations, suggesting a specific oncogenic process in these tumors. The two KIT-mutated cases 
carried SF3B1 mutations and were located on sun-protected mucosa, a genotype shared with genital and anorectal mucosal melanomas. Targetable mutations were observed in ERBB2, IDH1, MET, and MAP2K1 (one occurrence each). Mutational landscape of ConjMel characterizes distinct molecular subtypes with oncogenic drivers common with mucosal and skin melanomas. CTNNB1 mutations were associated with nevus-derived ConjMel. Concomitant KIT / SF3B1 mutations in sun-protected cases suggest a common tumorigenic process with genital and anorectal mucosal melanomas.

Keywords: conjunctival melanoma; sun exposure; nevus; primary acquired melanocytosis; $B R A F$; NRAS; KIT; CTNNB1

\section{Introduction}

Melanomas are a heterogeneous group of tumors that may arise from diverse tissues including glabrous or non-glabrous skin, mucosae, uvea, or leptomeninges. These melanoma subtypes present distinct clinical behaviors. For instance, cutaneous melanomas (CM) usually spread in lymph nodes before progressing to almost any viscera [1], while uveal melanomas undergo hematogenous spread and exhibit a strong liver tropism [2]. Ultraviolet (UV)-induced damage is another distinguishing factor between melanoma subtypes. CM are ultraviolet-induced tumors, typically exhibiting high mutation burden and proportion of CC > TT transitions, which are absent in most other melanomas [3]. Distinct genetic patterns also define these melanoma subtypes. Epithelia-associated melanomas such as cutaneous, acral, and mucosal melanomas frequently display mutations activating the MAPK, KIT, MITF, and/or TERT pathways, and genetic alterations inactivating tumor suppressor genes such as CDKN2A, NF1, TP53, and/or PTEN [3,4]. CM have been classified in four subtypes defined by BRAF mutations ( $50 \%$ of cases), NRAS/HRAS mutations $(\sim 25 \%)$, NF1 variants $(\sim 10 \%)$, and the absence of these variants $(\sim 15 \%)$. Clinical and genetic features further vary between $\mathrm{CM}$ subtypes, with $\mathrm{CM}$ arising from chronically sun-damaged skin such as facial CM occurring in older patients, which is associated with a higher frequency of BRAF ${ }^{\text {nonV600E }}, N R A S, N F 1$, and KIT mutations [5]. The frequencies of these genetic aberrations also differ depending on the tissue of origin of these melanomas, for instance, KIT mutations are more common in mucosal melanomas. Importantly, these mutations are not observed in uveal and leptomeningeal melanomas, which are instead commonly mutated in the G-protein coupled receptor pathway including GNAQ, GNA11, CYSLTR2, and PLCB4 [6]. Altogether, these genetic alterations influence clinical decisions for metastatic disease management with BRAF and MEK inhibitor treatment being suitable for patients with BRAF-mutated melanomas, while patients with KIT-mutated melanomas benefit from KIT inhibitors [7]. Furthermore, immune checkpoint inhibitors have shown a high activity in CM because of their high clonal mutation burden, whereas their efficacy is reduced in mucosal melanoma, a subtype carrying a much lower mutation burden [8,9].

Conjunctival melanoma (ConjMel) arises from conjunctiva, the ocular external mucosa, mostly within areas of primary acquired melanocytosis (PAM) ( $\sim 5 \%$ of cases), in conjunctival nevi ( $15 \%$ of cases) or de novo in $\sim 20 \%$ of cases [10-12]. ConjMel represents around $5 \%$ of ocular melanomas and $0.25 \%$ of all melanomas but its incidence has been increasing over the last decades with a suspected relationship to sunlight exposure [13,14]. ConjMel risk factors are close to those of CM including genetic predisposition, potential UV exposure at early ages, and fair skin [12]. Although ConjMel mostly occurs on sunlight-exposed areas, they may also appear on sunlight-protected areas (i.e., behind eyelids) [12,15]. Mitomycin $C$ instillations, interferon, and radiotherapy are often used in the adjuvant setting after tumor excision to reduce the risk of metastases, local recurrence rate, and therefore the risk of exenteration. Even with optimal local treatment, approximately $20-30 \%$ of ConjMel patients will eventually develop regional and visceral metastases with a pattern similar to CM $[10,16]$. Therefore, ConjMel is a potentially sight- and life-threatening disease. While the genetics of other melanomas and especially $\mathrm{CM}$ have been much described in recent 
years, there is a paucity of large cohort genetic ConjMel studies. Recent reports have shown that ConjMel presents an UV-associated mutational signature together with a high number of indels and copy number alterations [17-19]. Other reports have described BRAF activating mutations in approximately a third of patients, NRAS Q61 in 0 to $18 \%$, and KIT in less than 5\% [20-25]. The purpose of this study was to describe the ConjMel mutational landscape in order to identify specific oncogenic mechanisms and druggable targets.

\section{Materials and Methods}

\subsection{Sample Collection}

This study was approved by the Internal Review Board of Institut Curie. Tumors were deemed "non-sunlight-exposed" if the entire lesion was behind the eyelids, and "sunlightexposed" if at least a part of the lesion was on a sun-exposed area. All analyzed samples came from 47 independent archived formalin-fixed paraffin-embedded (FFPE) samples.

\subsection{DNA Extraction}

Samples were histologically reviewed by a pathologist before nucleic acid extraction in order to select samples with at least $30 \%$ of tumor cells. DNA was extracted by the Centre de Ressources Biologiques (Institut Curie, 26 rue d'Ulm, 75248 Paris, France, tumor biobank) from FFPE using the Nucleospin Tissue Kit (Macherey-Nagel GmbH \& Co. KG, Düren, Germany), then subsequently purified on Zymo-Spin IC to remove melanin (Zymo Research, Irvine, CA, USA). DNA concentrations were quantified by Qubit (Thermo Fisher Scientific, Waltham, MA, USA).

\subsection{Libraries Preparation and Sequencing}

Targeted-sequencing libraries were prepared using the Ion Ampliseq Comprehensive Cancer Panel (400 genes, 1.75 megabases (Mb), Thermo Fisher Scientific, Waltham, MA, USA) from $200 \mathrm{ng}$ of DNA. The full list of interrogated genes can be downloaded here: https:/ / assets.thermofisher.com/TFS-Assets/CSD/Reference-Materials/ion-ampliseq-cancer-panelgene-list.pdf; Last accessed on 30 June 2021. Libraries were $100 \mathrm{bp}$ paired-end multiplex sequenced on the Illumina HiSeq 2500 (Illumina Inc., San Diego, CA, USA).

\subsection{Sequencing Analyses and Mutation Calling}

Sequencing quality was assessed by FastQC (http:/ /www.bioinformatics.babraham. ac.uk/projects/fastqc/; Last accessed on 30 June 2021). Reads were aligned to the human genome (hg19) with Bowtie2 2.1.0 (http:/ / bowtie-bio.sourceforge.net/bowtie2/index. shtml; Last accessed 30 June 2021) [26]. PCR duplicates were removed using Picards Tool MarkDuplicates v1.97 (https:/ / broadinstitute.github.io/picard/; Last accessed on 30 June 2021). Variant calling for SNP and indels were performed using HaplotypeCaller [27] (https://gatk.broadinstitute.org/hc/en-us; Last accessed on 30 June 2021). Variants were annotated using ANNOVAR [28] (http:/ / annovar.openbioinformatics.org/ en/latest/; Last accessed on 30 June 2021) with the databases ensGene, avsnp147 [29], cosmic81 (https:/ / cancer.sanger.ac.uk/cosmic; Last accessed on 30 June 2021) [30], and popfreq all. Variants were filtered sequentially by (i) removing non-exonic variants; (ii) synonymous variants; (iii) variants with population frequency higher than $1 \%$ (ANNOVAR popfreq_all > 0.01); and (iv) variants covered with less than five reads of position depth (DP) and/or less than three reads of allele depth (AD) and/or a frequency (AD/DP) of less than $10 \%$. Variants from genes suspected to be tumor suppressor genes (BAP1, NF1, CDKN2A, ARID2, TET2, RB1, or PTEN) were classified following MutationTaster scores and only variants predicted as non-polymorphic were kept (http:/ / www.mutationtaster.org/; Last accessed on 30 June 2021) [31]. Mutations were described as recurrent in the COSMICv81 database if $\geq 3$ occurrences in eye samples and/or $\geq 10$ in skin and/or $\geq 15$ in the whole database. 


\subsection{Statistics}

Associations between qualitative features were tested using the Fisher's exact test, while association between age and mutational status was tested using the Mann-Whitney test. Analyses were carried out with the R software v 4.0.3 (http:/ / www.R-project.org/; Last accessed on 30 June 2021) [32] and a two-tailed $p<0.05$ was deemed significant.

\section{Results}

\subsection{Overview}

Samples from 47 ConjMel patients treated between May 2004 and June 2016 at the Institut Curie were sequenced with a commercial panel of 400 genes $(1.75 \mathrm{Mb})$ including genes implicated in melanoma oncogenesis. Clinical histories and pathology findings are described in Table 1 and Table S1. We did not find a family history of cancers, in particular skin and conjunctival melanoma. None of our cases presented clinically detectable Ota nevus or uveal melanoma. Median follow-up was of 59.8 months. Median age was 69 years (range 44-93 years) with an equilibrated sex-ratio (23 men for 24 women). Eight tumors $(17 \%)$ were entirely located in non-sunlight-exposed zones (i.e., behind the eyelid). They originated from primary acquired melanocytosis (PAM) in 24 cases (Figure 1;51\%), from nevi in eight cases $(17 \%)$, and de novo in 15 cases $(32 \%)$. The patients had a median of two surgeries (not including biopsies or brachytherapy, range 1-8, Table 1), 6/47 had an exenteration (13\%), 8/47 (17\%) suffered metastatic recurrences, and 17/47 (36\%) had passed away at the last follow up. Four patients (9\%) received local mitomycin C and 12 $(26 \%)$ received radiotherapy before sampling.
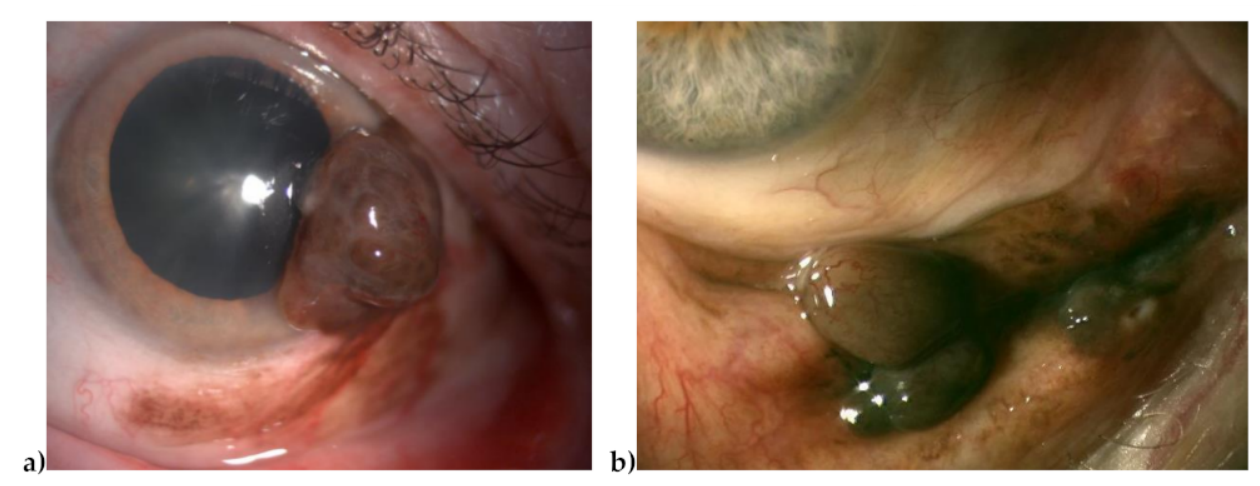

Figure 1. Two pictures of ConjMel originating at the limbus, from primary acquired melanocytosis ((a) case \#4), and inferior fornix ((b) case \#46).

\subsection{Mutated Genes}

Sequencing resulted in a median depth of $565 \times$ (range 190-3200 $\times$ ) and a median $20 \times$ coverage of $97.7 \%$ (range 69-99\%). After filtering out low depth variants and known polymorphisms, a median of 786 variants per case was observed, most of them probably being germline variants as tumor sequencing was not matched with germline (range 544-9016). Two sun-exposed tumors presented outlier mutation burdens with a 2.3 and 11.4-fold increase of variants, suggesting a different mutational process, but subsequent whole-exome sequencing showed an ultraviolet-related signature. Variant analysis then focused on (i) tumor suppressor genes and known melanoma hotspots; (ii) mutations known to be recurrent in the COSMIC pan-cancer database; and (iii) other oncogenic mutations, namely mutations of CBL, CTNNB1, RUNX1, SMARCA4, and TET2. More than half of the cases presented mutually exclusive activating mutations in known melanoma oncogenes such as BRAF p.G464/G466/G469/V600/K601 in 16 cases (34\%), NRAS p.G12/G13/Q61 in five cases (11\%), HRAS p.G12/G13 in two cases, and KIT p.L576P in two cases (Figure 2 and Table S2). Notably, BRAF p.G466E and p.G469R co-occurred with less potent HRAS p.G12S in case \#37. NF1 mutations were present in 17 cases including four $B R A F$-mutated samples. Typical uveal melanoma-related mutations were found in seven cases $(15 \%)$ : one 
case with GNAQ p.R183Q, one with GNA11 p.R183C, two with SF3B1 p.R625C/H, and three with $B A P 1$ missense/nonsense supposedly somatic mutations. No tumor presented concomitant variants in GNAQ/GNA11 and in SF3B1 or BAP1.

Table 1. Summary of clinical features.

\begin{tabular}{|c|c|}
\hline Characteristics & Values \\
\hline Total number of patients & 47 \\
\hline Median age at sampling (years) & 69 (range 44-93) \\
\hline \multicolumn{2}{|l|}{ Gender } \\
\hline Female & $24 / 47(51 \%)$ \\
\hline Male & $23 / 47(49 \%)$ \\
\hline \multicolumn{2}{|l|}{ Tumor location } \\
\hline Sun-exposed & $39 / 47(83 \%)$ \\
\hline Non-sun-exposed & $8 / 47(17 \%)$ \\
\hline \multicolumn{2}{|l|}{ Premalignant lesion } \\
\hline PAM & $24 / 47(51 \%)$ \\
\hline Nevus & $8 / 47(17 \%)$ \\
\hline De novo & $13 / 47(28 \%)$ \\
\hline Unknown & $2 / 47(4 \%)$ \\
\hline \multicolumn{2}{|l|}{ Tumor stage } \\
\hline $\mathrm{T} 1$ & $24 / 47(51 \%)$ \\
\hline $\mathrm{T} 2$ & $12 / 47(26 \%)$ \\
\hline T3 & $8 / 47(17 \%)$ \\
\hline unknown & $3 / 47(6 \%)$ \\
\hline \multicolumn{2}{|l|}{ Histology } \\
\hline Epithelioid & $21 / 47(45 \%)$ \\
\hline Spindle cells & $7 / 47(15 \%)$ \\
\hline Mixed & $13 / 47(28 \%)$ \\
\hline Unknown & $6 / 47(13 \%)$ \\
\hline \multicolumn{2}{|l|}{ Mitotic index } \\
\hline Low ( $<11$ figures $/ 10$ fields) & $18 / 47(38 \%)$ \\
\hline Intermediate (11-22 figures / 10 fields) & $8 / 47(17 \%)$ \\
\hline High ( $>22$ figures /10 fields) & $14 / 47(30 \%)$ \\
\hline \multicolumn{2}{|l|}{ Treatment } \\
\hline Median number of surgeries (range) & $2(1-8)$ \\
\hline Number of exenterations & $6 / 47(13 \%)$ \\
\hline \multicolumn{2}{|l|}{ Adjuvant treatment before sampling } \\
\hline adjuvant mitomycine $\mathrm{C}$ & $4 / 47(9 \%)$ \\
\hline adjuvant radiotherapy & $12 / 47(26 \%)$ \\
\hline Recurrences & \\
\hline Number of metastatic recurrences & $8 / 47(17 \%)$ \\
\hline
\end{tabular}

CTNNB1 was found mutated in eight cases (17\%). All eight mutations were located between codons 41 to 51 in the $\beta$-transducin repeat-containing protein $(\beta-\operatorname{TrCP})$ binding motif. CBL was found to be mutated in four cases (9\%). All mutations were missense variants located between codons 390 to 419 in the RING finger domain. Hotspot mutations of TP53 were found in four cases (9\%). Several mutations in the tumor suppressor genes were predicted to be deleterious including BAP1, NF1, CDKN2A, ARID2, TET2, RB1, PTEN, XPC, PBRM1, or ATR, but the definitive status of these genes could not be determined in the absence of germline sequencing. Finally, single occurrences of targetable oncogenic mutations were observed in ERBB2 p.S310F, IDH1 p.R132C, MET p.T1010I, and MAP2K1 p.P124S. 


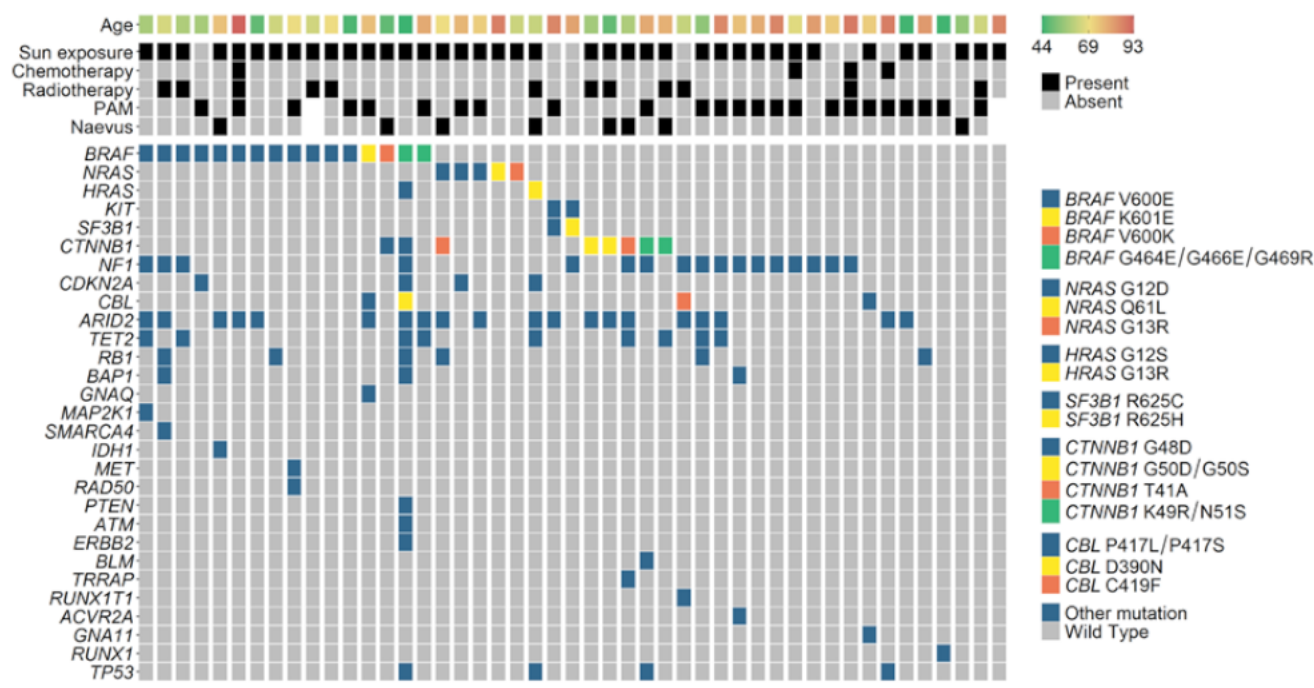

Figure 2. OncoPrint of mutations in melanoma-associated genes. PAM: primary-acquired melanocytosis.

\subsection{Correlation with Clinical and Pathological Findings}

The eight tumors originating from conjunctival nevi were enriched in CTNNB1 mutations (five out of eight; $63 \%$ vs. three out of 39 non-nevi MelConj (8\%); Fisher's exact test $p=0.001$ ). Interestingly, 5/8 CTNNB1-mutated cases were devoid of BRAF, RAS, NF1, or KIT mutations. No specific genetic characteristic was found in PAM-originating ConjMel. Sunlight-exposed ConjMel was more often associated with BRAF, HRAS, NRAS, and CTNNB1 mutations than unexposed ConjMel (66.7\% vs. $12.5 \%$, respectively; Fisher's exact test $p=0.007)$. Among the eight non-sunlight-exposed ConjMel, samples from two patients of more than 80 years bore the only two KIT activating mutations found in the series ( $2 / 8$ unexposed cases vs. $0 / 39$ exposed cases; Fisher's exact test $p=0.026)$. These KIT mutations co-occurred with the only two SF3B1 oncogenic mutations found in the series. BRAF-mutated and CDKN2A-mutated ConjMel occurred in younger patients with median ages of 64 years vs. 73 years (Figure 3; Mann-Whitney test $p=0.070$ ) and 60 years vs. 69 years $(p=0.18)$, respectively, while NF1-mutated cases only tended to be older (73 years vs. 69 years; $p=0.55$ ). The eight cases with metastatic recurrences were RASm (three out of the six RASm cases), BRAFm (three out of 16), and RAS/BRAFwt (two out of 25). No link was found between genetic characteristics and treatment including prior exposures to mitomycin $\mathrm{C}$ treatment and radiotherapy.

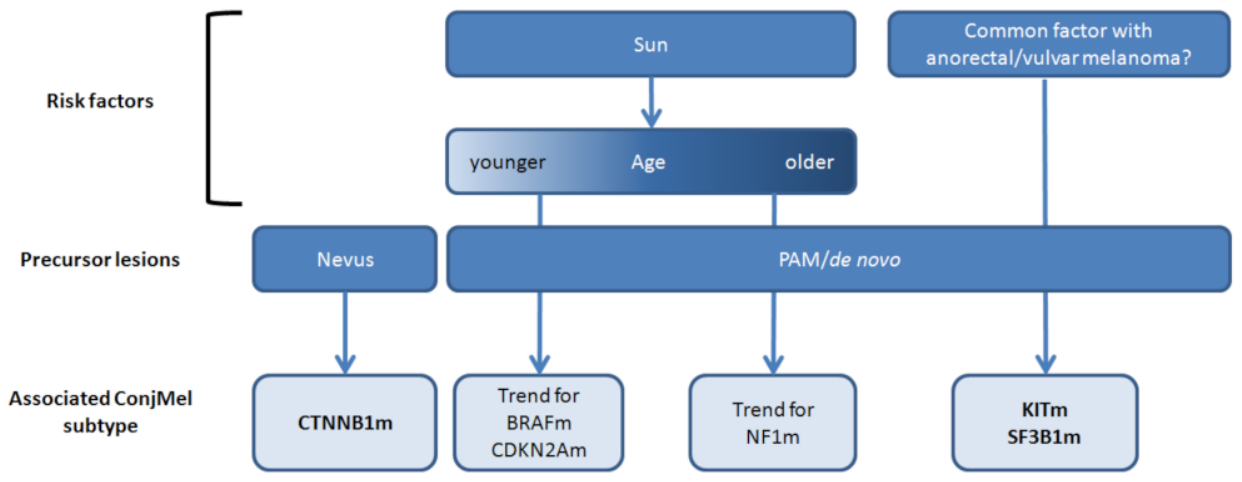

Figure 3. Proposal of molecular classification according to potential etiological factors.

\section{Discussion}

Accounting for only $\sim 5 \%$ of ocular melanomas, the rarity and smallness of ConjMel have impeded large genetic studies. Our study describes the mutational analysis of 400 genes in one of the largest cohorts ever published. In our series, ConjMel shared 
features with chronically sun-damaged $C M$ including older age at diagnosis and high incidences of NRAS, KIT, BRAF non-V600, and NF1 mutations. These observations provide further evidence for a potential role of chronic, lifelong sunlight exposure in conjunctival melanomagenesis [12]. Indeed, UV-driven DNA damage is predominant in mucosal melanomas of conjunctival origin $[16,17]$. On the other hand, ConjMel also presented similarities with mucosal melanomas as they have been reported to display a high number of indels and copy number alterations [19]. Taken together, our data support that ConjMel is a biologically distinct, heterogeneous group of melanomas presenting a mixed phenotype with features of mucosal melanomas associated with genetic scars of chronic UV exposure similar to iris melanomas, a subset of uveal melanomas displaying a UV-induced, high mutation burden $[33,34]$. Similar to $C M$, such pathogenesis results in genetically defined ConjMel subsets in younger patients affected by BRAF- or CDKN2A-mutated ConjMel, while older patients carried NF1-mutated ConjMel, although the age difference was found to not be statistically significant [6]. However, the absence of germline sequencing in our study impedes definitive conclusions on the origin of inactivating variants in tumor suppressive genes such as CDKN2A or NF1. Recurrent mutations demonstrated a prominence of $M A P K$ pathway activation, primarily through $N R A S$ and $B R A F$ activation, confirming previous reports [24,35]. ConjMel cases with $R A S$ mutations may be of poor prognosis, but small sample size prevented us from drawing definitive conclusions. However, such association has also been reported in skin melanomas with NRAS mutation being identified as an independent predictor of disease progression [36]. We identified the same four subtypes as in CM, defined by BRAF (in 32\% of cases), RAS (13\% including the first report of NRAS p.G12R and HRAS activating mutations in ConjMel), NF1 mutations (22\%, without concomitant $B R A F / R A S$ mutation), or by the absence of these alterations (triple wild-type; $33 \%$ ). This observation further solidifies the close relationship between CM and ConjMel. Overall, BRAF mutation incidence was at the intermediary level compared with other melanomas, ranging from $\sim 50 \%$ in $C M$, and $\sim 10 \%$ in mucosal to $0 \%$ in uveal melanomas [24,35]. As in CM, BRAF mutations were observed in younger ConjMel patients, confirming observations from Larsen and colleagues $[4,35]$ including low activity BRAFnonV600E mutations (p.G464E, p.G466E, pS467L, and p.G469R). Similarly, we observed a subset of NF1-mutated ConjMel, mutually exclusive with other MAPK-activating mutations, in similar proportions than in CM [3,4].

The triple-wild-type cohort appeared to be heterogeneous with some cases carrying CTNNB1 mutations, while others presented both SF3B1/KIT mutations. CTNNB1, coding for $\beta$-catenin, was found mutated in $15 \%$ of ConjMel cases, while they were exceptional in CM and mucosal melanomas ( 5\%) [4]. CTNNB1 mutations were mutually exclusive from the other oncogenic mutations in most cases and associated with pre-existing nevi, suggesting a specific melanomagenesis process. However, the study of the origin of these cases was limited by the absence of reported analysis of pre-existing lesions in clinical files from two of our 47 patients. Of interest, CTNNB1 mutations occur in an unusual type of melanocytic nevus, termed "deep penetrating-nevus" (DPN) occurring in the skin, the conjunctiva and in extremely rare melanomas derived from such DPN $[37,38]$. Among the eight CTNNB1-mutated tumors, clear cut evolution from DPN could not be confirmed (or ruled out) histopathologically with complete certainty, probably because of the evolution of the invasive component. CTNNB1 mutations impede $\beta$-catenin degradation, provoke nuclear translocation, and promote transcription of target genes. Two samples presented T41A, a known oncogenic mutation present in half of desmoid tumors (1252/2422 cases in COSMIC). Other ConjMel presented missense variants in the $\beta$-TrCP binding motif between codons 48 to 51 . Although less frequent than mutations in codons 32 to 45 , variants in codons 48 to 51 have been identified in several other rare tumor types such as anaplastic thyroid carcinomas [39], sinonasal NK-T cell lymphomas [40], gastrointestinal carcinoid tumors [41], and gastric carcinomas intestinal type [42], supporting their oncogenic role in ConjMel. Two sun-protected ConjMel tumors presented concomitant KIT and SF3B1 activating mutations. While KIT mutations have been observed at a similar 
overall rate in CM [3,4], they did not overlap with SF3B1 mutations in these tumors. Rare activating KIT mutations and SF3B1 mutations have been previously reported in ConjMel cases $[23-25,43,44]$. Although not emphasized in previous publications, some mucosal melanomas may carry concomitant KIT/SF3B1 mutations [45-48]. Interestingly, all these cases were sun-protected mucosal melanomas with high incidence of these KIT/SF3B1 co-mutations in $\sim 20-40 \%$ of anorectal melanomas and $\sim 33 \%$ of vulvar or genitourinary melanomas. KIT oncogenic mutations activate the downstream PI3K and MAPK pathways, while SF3B1 mutations induce an alternative mRNA splicing. These two mutations may cooperate to induce the cancer phenotype as observed in around $20-25 \%$ of uveal melanomas [49]. Our data suggest that mutant KIT/SF3B1 co-occurrence may be a specific feature of a subset of mucosal melanomas including ConjMel, anorectal, and genitourinary melanomas. Some cases presented with mutations usually linked to uveal melanomas (GNAQ, GNA11, SF3B1, BAP1), but these mutations did not co-occur, suggesting a different tumorigenesis process than in UM. The tumorigenesis of these tumors may be similar to that of rare skin melanomas exhibiting these UM-like mutations. Other rare recurrent, targetable, oncogenic mutations were found in our cohort including IDH1 R132C, ERBB2 S310F, MET T1010I, and MAP2K1 P124S [43,50-53]. CBL missense variants were present in $6 \%$ of cases. CBL codes for an E3-ubiquitin ligase that promotes the ubiquitination of signaling proteins through the catalytic activity of its RING finger domain. Oncogenic mutations in codons 390,417, and 419, as found in our cohort, belong to the RING domain and have been previously reported in myelodysplasia [54], acute myeloid leukemia [55], myeloproliferative syndromes [56], and chronic myelomonocytic leukemia [57].

\section{Conclusions}

Taken together, our data support the fact that ConjMel is a biologically distinct group of melanomas with features reflecting their mucosal origins as well as their chronic exposure to sunlight. Furthermore, this work promotes the emergence of personalized therapies for ConjMel patients. High mutation burden urges the use of checkpoint inhibitors in the metastatic as well as in the adjuvant settings while BRAF and KIT activating mutations qualify these patients to BRAF/MEK and KIT inhibitions. Ultimately, the discovery of new oncogenic, targetable mutations in IDH1, ERBB2, MET, and MAP2K1 opens new therapeutic avenues as new pharmacological inhibitors are developed.

Supplementary Materials: The following are available online at https:/ / www.mdpi.com/article/ 10.3390 / cancers13153836/s1, Table S1: Patient and tumor features, Table S2: Variant calling in the conjunctive melanoma series.

Author Contributions: Conceptualization, S.G., N.C., S.R.-R., M.-H.S. and M.R.; Methodology, S.R.R., M.-H.S. and M.R.; Formal analysis, S.G., A.H., R.B., S.D., I.B., V.R., S.B. and M.R.; Data curation, S.G., A.H. and M.R.; Writing—original draft preparation, S.G., K.B. and M.R.; Writing-review and editing, S.G., A.H., K.B., N.C., R.B., S.D., I.B., V.R., S.B., R.M., S.R.-R., M.-H.S. and M.R.; Supervision, M.R. and S.R.-R.; Project administration, M.R., N.C. and S.R.-R.; Funding acquisition, R.M., M.-H.S. and S.R.-R. All authors have read and agreed to the published version of the manuscript.

Funding: This research was funded by the European Commission under the Horizon 2020 program, grant number 667787, by the Institut National De La Santé Et De La Recherche Médicale (INSERM), by the Institut Curie, the Ligue Nationale Contre Le Cancer (Labellisation), the European Research Council (ERC-ADG-2014 671262), and Cancer Research UK (A27412 and A22902).

Institutional Review Board Statement: The study was conducted according to the guidelines of the Declaration of Helsinki, and approved by the Ocular Melanoma Institutional Review Board of Institut Curie (MC-1-2014, 7 November 2014).

Informed Consent Statement: Informed consent was obtained from all subjects involved in the study.

Data Availability Statement: Sequencing data available on demand from the corresponding author.

Acknowledgments: The authors thank the patients and their family members. The authors acknowledge support from the Institut Curie for sample collection, banking, and processing, the Biological 
Resource Center and its members, the Unite de Pharmacogénomique and the Histology Laboratory, Department of Pathology and its members. The authors thank Olivier Ganier for his attentive review. The authors thank Leanne De Koning for this attentive review.

Conflicts of Interest: M.R. received research grants from Bristol-Myers Squibb and Merck Sharp \& Dohme. The other authors declare no conflict of interest.

\section{References}

1. Tas, F. Metastatic behavior in melanoma: Timing, pattern, survival, and influencing factors. J. Oncol. 2012, 2012, 647684. [CrossRef]

2. Collaborative Ocular Melanoma Study Group. Assessment of metastatic disease status at death in 435 patients with large choroidal melanoma in the Collaborative Ocular Melanoma Study (COMS): COMS report no. 15. Arch. Ophthalmol. 2001, 119, 670-676. [CrossRef]

3. Hayward, N.K.; Wilmott, J.S.; Waddell, N.; Johansson, P.A.; Field, M.A.; Nones, K.; Patch, A.M.; Kakavand, H.; Alexandrov, L.B.; Burke, H.; et al. Whole-genome landscapes of major melanoma subtypes. Nature 2017, 545, 175-180. [CrossRef]

4. The Cancer Genome Atlas Network. Genomic Classification of Cutaneous Melanoma. Cell 2015, 161, 1681-1696. [CrossRef]

5. Shain, A.H.; Bastian, B.C. From melanocytes to melanomas. Nat. Rev. Cancer 2016, 16, 345-358. [CrossRef] [PubMed]

6. Jager, M.J.; Shields, C.L.; Cebulla, C.M.; Abdel-Rahman, M.H.; Grossniklaus, H.E.; Stern, M.H.; Carvajal, R.D.; Belfort, R.N.; Jia, R.; Shields, J.A.; et al. Uveal melanoma. Nat. Rev. Dis. Primers 2020, 6, 24. [CrossRef] [PubMed]

7. Guo, J.; Carvajal, R.D.; Dummer, R.; Hauschild, A.; Daud, A.; Bastian, B.C.; Markovic, S.N.; Queirolo, P.; Arance, A.; Berking, C.; et al. Efficacy and safety of nilotinib in patients with KIT-mutated metastatic or inoperable melanoma: Final results from the global, single-arm, phase II TEAM trial. Ann. Oncol. Off. J. Eur. Soc. Med. Oncol. 2017, 28, 1380-1387. [CrossRef] [PubMed]

8. D'Angelo, S.P.; Larkin, J.; Sosman, J.A.; Lebbe, C.; Brady, B.; Neyns, B.; Schmidt, H.; Hassel, J.C.; Hodi, F.S.; Lorigan, P.; et al. Efficacy and Safety of Nivolumab Alone or in Combination with Ipilimumab in Patients with Mucosal Melanoma: A Pooled Analysis. J. Clin. Oncol. Off. J. Am. Soc. Clin. Oncol. 2017, 35, 226-235. [CrossRef]

9. Thierauf, J.; Veit, J.A.; Hess, J.; Treiber, N.; Lisson, C.; Weissinger, S.E.; Bommer, M.; Hoffmann, T.K. Checkpoint inhibition for advanced mucosal melanoma. Eur. J. Dermatol. EJD 2017, 27, 160-165. [CrossRef]

10. Missotten, G.S.; Keijser, S.; De Keizer, R.J.; De Wolff-Rouendaal, D. Conjunctival melanoma in the Netherlands: A nationwide study. Investig. Ophthalmol. Vis. Sci. 2005, 46, 75-82. [CrossRef] [PubMed]

11. Shields, J.A.; Shields, C.L.; Mashayekhi, A.; Marr, B.P.; Benavides, R.; Thangappan, A.; Phan, L.; Eagle, R.C., Jr. Primary acquired melanosis of the conjunctiva: Experience with 311 eyes. Trans. Am. Ophthalmol. Soc. 2007, 105, 61-71. [PubMed]

12. Shields, C.L.; Fasiuddin, A.F.; Mashayekhi, A.; Shields, J.A. Conjunctival nevi: Clinical features and natural course in 410 consecutive patients. Arch. Ophthalmol. 2004, 122, 167-175. [CrossRef]

13. Wong, J.R.; Nanji, A.A.; Galor, A.; Karp, C.L. Management of conjunctival malignant melanoma: A review and update. Expert Rev. Ophthalmol. 2014, 9, 185-204. [CrossRef]

14. Triay, E.; Bergman, L.; Nilsson, B.; All-Ericsson, C.; Seregard, S. Time trends in the incidence of conjunctival melanoma in Sweden. Br. J. Ophthalmol. 2009, 93, 1524-1528. [CrossRef] [PubMed]

15. Shields, C.L.; Markowitz, J.S.; Belinsky, I.; Schwartzstein, H.; George, N.S.; Lally, S.E.; Mashayekhi, A.; Shields, J.A. Conjunctival melanoma: Outcomes based on tumor origin in 382 consecutive cases. Ophthalmology 2011, 118, 389-395. [CrossRef]

16. Kenawy, N.; Lake, S.L.; Coupland, S.E.; Damato, B.E. Conjunctival melanoma and melanocytic intra-epithelial neoplasia. Eye 2013, 27, 142-152. [CrossRef]

17. Rivolta, C.; Royer-Bertrand, B.; Rimoldi, D.; Schalenbourg, A.; Zografos, L.; Leyvraz, S.; Moulin, A. UV light signature in conjunctival melanoma; not only skin should be protected from solar radiation. J. Hum. Genet. 2016, 61, 361-362. [CrossRef]

18. Demirci, H.; Demirci, F.Y.; Ciftci, S.; Elner, V.M.; Wu, Y.M.; Ning, Y.; Chinnaiyan, A.; Robinson, D.R. Integrative Exome and Transcriptome Analysis of Conjunctival Melanoma and Its Potential Application for Personalized Therapy. JAMA Ophthalmol. 2019. [CrossRef] [PubMed]

19. Mundra, P.A.; Dhomen, N.; Rodrigues, M.; Mikkelsen, L.H.; Cassoux, N.; Brooks, K.; Valpione, S.; Reis-Filho, J.S.; Heegaard, S.; Stern, M.H.; et al. Ultraviolet radiation drives mutations in a subset of mucosal melanomas. Nat. Commun. 2021, 12, 259. [CrossRef]

20. Alessandrini, L.; Parrozzani, R.; Bertorelle, R.; Valentini, E.; Candiotto, C.; Giacomelli, L.; Midena, E.; Blandamura, S. C-Kit SCF receptor (CD117) expression and KIT gene mutation in conjunctival pigmented lesions. Acta Ophthalmol. 2013, 91, e641-e645. [CrossRef]

21. Cao, J.; Heijkants, R.C.; Jochemsen, A.G.; Dogrusoz, M.; de Lange, M.J.; van der Velden, P.A.; van der Burg, S.H.; Jager, M.J.; Verdijk, R.M. Targeting of the MAPK and AKT pathways in conjunctival melanoma shows potential synergy. Oncotarget 2017, 8, 58021-58036. [CrossRef]

22. Larsen, A.C.; Dahmcke, C.M.; Dahl, C.; Siersma, V.D.; Toft, P.B.; Coupland, S.E.; Prause, J.U.; Guldberg, P.; Heegaard, S. A Retrospective Review of Conjunctival Melanoma Presentation, Treatment, and Outcome and an Investigation of Features Associated With BRAF Mutations. JAMA Ophthalmol. 2015, 133, 1295-1303. [CrossRef] [PubMed]

23. Scholz, S.L.; Cosgarea, I.; Susskind, D.; Murali, R.; Moller, I.; Reis, H.; Leonardelli, S.; Schilling, B.; Schimming, T.; Hadaschik, E.; et al. NF1 mutations in conjunctival melanoma. Br. J. Cancer 2018, 118, 1243-1247. [CrossRef] 
24. Griewank, K.G.; Westekemper, H.; Murali, R.; Mach, M.; Schilling, B.; Wiesner, T.; Schimming, T.; Livingstone, E.; Sucker, A.; Grabellus, F.; et al. Conjunctival melanomas harbor BRAF and NRAS mutations and copy number changes similar to cutaneous and mucosal melanomas. Clin. Cancer Res. Off. J. Am. Assoc. Cancer Res. 2013, 19, 3143-3152. [CrossRef] [PubMed]

25. Beadling, C.; Jacobson-Dunlop, E.; Hodi, F.S.; Le, C.; Warrick, A.; Patterson, J.; Town, A.; Harlow, A.; Cruz, F., 3rd; Azar, S.; et al. KIT gene mutations and copy number in melanoma subtypes. Clin. Cancer Res. Off. J. Am. Assoc. Cancer Res. 2008, 14, 6821-6828. [CrossRef]

26. Langmead, B.; Salzberg, S.L. Fast gapped-read alignment with Bowtie 2. Nat. Methods 2012, 9, 357-359. [CrossRef] [PubMed]

27. Lescai, F.; Marasco, E.; Bacchelli, C.; Stanier, P.; Mantovani, V.; Beales, P. Identification and validation of loss of function variants in clinical contexts. Mol. Genet. Genom. Med. 2014, 2, 58-63. [CrossRef]

28. Wang, K.; Li, M.; Hakonarson, H. ANNOVAR: Functional annotation of genetic variants from high-throughput sequencing data. Nucleic Acids Res. 2010, 38, e164. [CrossRef] [PubMed]

29. Sherry, S.T.; Ward, M.; Sirotkin, K. dbSNP-database for single nucleotide polymorphisms and other classes of minor genetic variation. Genome Res. 1999, 9, 677-679. [PubMed]

30. Forbes, S.A.; Beare, D.; Gunasekaran, P.; Leung, K.; Bindal, N.; Boutselakis, H.; Ding, M.; Bamford, S.; Cole, C.; Ward, S.; et al. COSMIC: Exploring the world's knowledge of somatic mutations in human cancer. Nucleic Acids Res. 2015, 43, D805-D811. [CrossRef] [PubMed]

31. Schwarz, J.M.; Cooper, D.N.; Schuelke, M.; Seelow, D. MutationTaster2: Mutation prediction for the deep-sequencing age. Nat. Methods 2014, 11, 361-362. [CrossRef]

32. R Development Core Team. R: A Language and Environment for Statistical Computing; R Foundation for Statistical Computing: Vienna, Austria, 2013.

33. Karlsson, J.; Nilsson, L.M.; Mitra, S.; Alsen, S.; Shelke, G.V.; Sah, V.R.; Forsberg, E.M.V.; Stierner, U.; All-Eriksson, C.; Einarsdottir, B.; et al. Molecular profiling of driver events in metastatic uveal melanoma. Nat. Commun. 2020, 11, 1894. [CrossRef] [PubMed]

34. Van Poppelen, N.M.; Vaarwater, J.; Mudhar, H.S.; Sisley, K.; Rennie, I.G.; Rundle, P.; Brands, T.; van den Bosch, Q.C.C.; Mensink, H.W.; de Klein, A.; et al. Genetic Background of Iris Melanomas and Iris Melanocytic Tumors of Uncertain Malignant Potential. Ophthalmology 2018, 125, 904-912. [CrossRef] [PubMed]

35. Larsen, A.C.; Dahl, C.; Dahmcke, C.M.; Lade-Keller, J.; Siersma, V.D.; Toft, P.B.; Coupland, S.E.; Prause, J.U.; Guldberg, P.; Heegaard, S. BRAF mutations in conjunctival melanoma: Investigation of incidence, clinicopathological features, prognosis and paired premalignant lesions. Acta Ophthalmol. 2016, 94, 463-470. [CrossRef]

36. Heppt, M.V.; Siepmann, T.; Engel, J.; Schubert-Fritschle, G.; Eckel, R.; Mirlach, L.; Kirchner, T.; Jung, A.; Gesierich, A.; Ruzicka, T.; et al. Prognostic significance of BRAF and NRAS mutations in melanoma: A German study from routine care. BMC Cancer 2017, 17, 536. [CrossRef] [PubMed]

37. Sekoranja, D.; Vergot, K.; Hawlina, G.; Pizem, J. Combined deep penetrating nevi of the conjunctiva are relatively common lesions characterised by BRAFV600E mutation and activation of the beta catenin pathway: A clinicopathological analysis of 34 lesions. Br. J. Ophthalmol. 2020, 104, 1016-1021. [CrossRef]

38. Van Ipenburg, J.A.; Damman, J.; Paridaens, D.; Verdijk, R.M. Histopathological and Molecular Features of a Conjunctival Caruncular Deep Penetrating Nevus. Ocul. Oncol. Pathol. 2020, 6, 293-296. [CrossRef]

39. Garcia-Rostan, G.; Tallini, G.; Herrero, A.; D’Aquila, T.G.; Carcangiu, M.L.; Rimm, D.L. Frequent mutation and nuclear localization of beta-catenin in anaplastic thyroid carcinoma. Cancer Res. 1999, 59, 1811-1815. [PubMed]

40. Hongyo, T.; Hoshida, Y.; Nakatsuka, S.; Syaifudin, M.; Kojya, S.; Yang, W.I.; Min, Y.H.; Chan, H.; Kim, C.H.; Harabuchi, Y.; et al. p53, K-ras, c-kit and beta-catenin gene mutations in sinonasal NK/T-cell lymphoma in Korea and Japan. Oncol. Rep. 2005, 13, 265-271.

41. Fujimori, M.; Ikeda, S.; Shimizu, Y.; Okajima, M.; Asahara, T. Accumulation of beta-catenin protein and mutations in exon 3 of beta-catenin gene in gastrointestinal carcinoid tumor. Cancer Res. 2001, 61, 6656-6659. [PubMed]

42. Ogasawara, N.; Tsukamoto, T.; Mizoshita, T.; Inada, K.; Cao, X.; Takenaka, Y.; Joh, T.; Tatematsu, M. Mutations and nuclear accumulation of beta-catenin correlate with intestinal phenotypic expression in human gastric cancer. Histopathology 2006, 49, 612-621. [CrossRef] [PubMed]

43. Mikkelsen, L.H.; Maag, E.; Andersen, M.K.; Kruhoffer, M.; Larsen, A.C.; Melchior, L.C.; Toft, P.B.; von Buchwald, C.; Wadt, K.; Heegaard, S. The molecular profile of mucosal melanoma. Melanoma Res. 2020, 30, 533-542. [CrossRef]

44. Van Poppelen, N.M.; van Ipenburg, J.A.; van den Bosch, Q.; Vaarwater, J.; Brands, T.; Eussen, B.; Magielsen, F.; Dubbink, H.J.; Paridaens, D.; Brosens, E.; et al. Molecular Genetics of Conjunctival Melanoma and Prognostic Value of TERT Promoter Mutation Analysis. Int. J. Mol. Sci. 2021, 22, 5784. [CrossRef]

45. Yang, H.M.; Hsiao, S.J.; Schaeffer, D.F.; Lai, C.; Remotti, H.E.; Horst, D.; Mansukhani, M.M.; Horst, B.A. Identification of recurrent mutational events in anorectal melanoma. Mod. Pathol. Off. J. United States Can. Acad. Pathol. Inc. 2017, 30, 286-296. [CrossRef] [PubMed]

46. Hintzsche, J.D.; Gorden, N.T.; Amato, C.M.; Kim, J.; Wuensch, K.E.; Robinson, S.E.; Applegate, A.J.; Couts, K.L.; Medina, T.M.; Wells, K.R.; et al. Whole-exome sequencing identifies recurrent SF3B1 R625 mutation and comutation of NF1 and KIT in mucosal melanoma. Melanoma Res. 2017, 27, 189-199. [CrossRef] [PubMed] 
47. Zehir, A.; Benayed, R.; Shah, R.H.; Syed, A.; Middha, S.; Kim, H.R.; Srinivasan, P.; Gao, J.; Chakravarty, D.; Devlin, S.M.; et al. Mutational landscape of metastatic cancer revealed from prospective clinical sequencing of 10,000 patients. Nat. Med. 2017, 23, 703-713. [CrossRef] [PubMed]

48. Newell, F.; Kong, Y.; Wilmott, J.S.; Johansson, P.A.; Ferguson, P.M.; Cui, C.; Li, Z.; Kazakoff, S.H.; Burke, H.; Dodds, T.J.; et al. Whole-genome landscape of mucosal melanoma reveals diverse drivers and therapeutic targets. Nat. Commun. 2019, 10, 3163. [CrossRef]

49. Robertson, A.G.; Shih, J.; Yau, C.; Gibb, E.A.; Oba, J.; Mungall, K.L.; Hess, J.M.; Uzunangelov, V.; Walter, V.; Danilova, L.; et al. Integrative Analysis Identifies Four Molecular and Clinical Subsets in Uveal Melanoma. Cancer Cell 2017, 32, 204-220.e215. [CrossRef] [PubMed]

50. Lowery, M.A.; Abou-Alfa, G.K.; Burris, H.A.; Janku, F.; Shroff, R.T.; Cleary, J.M.; Azad, N.S.; Goyal, L.; Maher, E.A.; Gore, L.; et al. Phase I study of AG-120, an IDH1 mutant enzyme inhibitor: Results from the cholangiocarcinoma dose escalation and expansion cohorts. J. Clin. Oncol. 2017, 35, 4015. [CrossRef]

51. Chumsri, S.; Weidler, J.; Ali, S.; Balasubramanian, S.; Wallweber, G.; DeFazio-Eli, L.; Chenna, A.; Huang, W.; DeRidder, A.; Goicocheal, L.; et al. Prolonged Response to Trastuzumab in a Patient With HER2-Nonamplified Breast Cancer With Elevated HER2 Dimerization Harboring an ERBB2 S310F Mutation. J. Natl. Compr. Cancer Netw. JNCCN 2015, 13, 1066-1070. [CrossRef]

52. Liu, S.; Meric-Bernstam, F.; Parinyanitikul, N.; Wang, B.; Eterovic, A.K.; Zheng, X.; Gagea, M.; Chavez-MacGregor, M.; Ueno, N.T.; Lei, X.; et al. Functional consequence of the MET-T1010I polymorphism in breast cancer. Oncotarget 2015, 6, $2604-2614$. [CrossRef] [PubMed]

53. Carlino, M.S.; Fung, C.; Shahheydari, H.; Todd, J.R.; Boyd, S.C.; Irvine, M.; Nagrial, A.M.; Scolyer, R.A.; Kefford, R.F.; Long, G.V.; et al. Preexisting MEK1P124 mutations diminish response to BRAF inhibitors in metastatic melanoma patients. Clin. Cancer Res. Off. J. Am. Assoc. Cancer Res. 2015, 21, 98-105. [CrossRef]

54. Papaemmanuil, E.; Gerstung, M.; Malcovati, L.; Tauro, S.; Gundem, G.; Van Loo, P.; Yoon, C.J.; Ellis, P.; Wedge, D.C.; Pellagatti, A.; et al. Clinical and biological implications of driver mutations in myelodysplastic syndromes. Blood 2013, 122, 3616-3627. [CrossRef]

55. Papaemmanuil, E.; Gerstung, M.; Bullinger, L.; Gaidzik, V.I.; Paschka, P.; Roberts, N.D.; Potter, N.E.; Heuser, M.; Thol, F.; Bolli, N.; et al. Genomic Classification and Prognosis in Acute Myeloid Leukemia. N. Engl. J. Med. 2016, 374, $2209-2221$. [CrossRef] [PubMed]

56. Grand, F.H.; Hidalgo-Curtis, C.E.; Ernst, T.; Zoi, K.; Zoi, C.; McGuire, C.; Kreil, S.; Jones, A.; Score, J.; Metzgeroth, G.; et al. Frequent CBL mutations associated with 11q acquired uniparental disomy in myeloproliferative neoplasms. Blood 2009, 113, 6182-6192. [CrossRef]

57. Bernard, V.; Gebauer, N.; Dinh, T.; Stegemann, J.; Feller, A.C.; Merz, H. Applicability of next-generation sequencing to decalcified formalin-fixed and paraffin-embedded chronic myelomonocytic leukaemia samples. Int. J. Clin. Exp. Pathol. 2014, 7, 1667-1676. [PubMed] 